\title{
Fashion Business Sustainability for Fashion Designers in the Indonesian Fashion Industry
}

\author{
Nadia Putri Agusalim \\ PT. Timur Megah Steel \\ nadia_putri333@hotmail.com \\ https://doi.org/10.37715/rmbe.v1i2.2423
}

\begin{abstract}
The fashion industry remains as one of the most highly competitive industries where many fashion designers may find it difficult to establish sustainable fashion businesses. Navigating through the fashion business and ensuring business success, growth and long-term sustainability were generally considered to be the ultimate goal and biggest challenge many fashion designers continue to struggle with. This study was aimed to determine all key factors that are integral and contribute to fashion business sustainability by presenting findings provided by three Indonesian fashion designer's responses to the issue of fashion business sustainability, the various challenges, and what factors are needed to ensure a long lasting through semistructured in-depth interviews. Overall findings revealed the need for fashion designers to have an entrepreneurial mindset and for fashion businesses to possess all sustainable business key factors in various aspects ranging from design, business and the various qualities from the fashion designer themselves, while also taking account of the external state which was set in the Indonesian fashion industry for business sustainability and organic business growth. Fashion designers who controls all these factors will have a significantly higher chance of sustainability while competing with other fashion businesses.
\end{abstract}

Keywords-Include Fashion Designer, Fashion Business Sustainability, Sustainable Business Key Factors, Indonesian Fashion Industry.

\section{Introduction}

In form of proof supporting the situation, findings in 2014 reported that approximately 1 out of 4 fashion designers were self-employed (Benson, 2017) and more than likely fashion designers who are skilled and business savvy would have preference to work independently as self-employed fashion designers should possess both a strong business acumen and creativity (Benson, 2017). Considering the fact that this particular type of scenario will be unlikely to stop anytime soon, proper education, guidance and experience are needed for fashion designers who wish to become capable entrepreneurs to successfully start and run a fashion business that could compete and grow in a notoriously saturated industry known to be especially challenging for independent fashion business owners.

The primary focus on this research lies in the identification and determination of sustainable fashion business key factors to ensure not only the survival, but also the sustainability and further growth of independent fashion business labels with varieties explored in accordance to different business circumstances. The primary purpose of this study focuses to identify and determine all necessary key factors for acheiving fashion business sustainability applicable for fashion design entrepreneurs to ensure their business success and longevity as the end goal.

2. Literature Review

2.1 Initial Research

The Initial research conducted by Ünay and Zehir (2012) emphasizes the importance of innovation management for both fashion entrepreneurs and the fashion business. The combination between innovation dynamics entrepreneurship contributes to competitive advantage in a fashion business however the focus point is put on how creativity and innovation implemented in fashion design and business approach can work harmoniously well together when entrepreneurship is involved and management is done well. Study results are relevant in the aspects of utilizing the combination of innovation and entrepreneurship as a competitive advantage and strategic 
approach in addition to exploring the relation between innovation and the psychology of fashion design entrepreneurs.

Initial research conducted by Mills (2012) bridges between entrepreneurship education and the fashion business start-up in the New Zealand designer fashion industry (DFI). The highlight of this study emphasizes combining design education with the practice of enterprise development required for aspiring fashion business owners in order to better attain business success. Study results are relevant in providing plentiful data in the context of fashion design students in regards to their perspectives towards fashion business, entrepreneurial education, and design education in the DFI for further study and exploration.

\subsection{Theoretical Definitions}

\subsubsection{Fashion Design}

Deriving from the word "fashion", the term "fashion design" is defined as the artistic application of aesthetic, beauty, and design elements onto clothing an fashion apparel through ideas and concepts. Interestingly fashion design may be perceived to be a process-oriented concept rather than product-oriented, as a design shifts between multiple forms ranging depending on process resulting in a final product (Smal \& Lavelle, 2011). The fashion design process outlined below involves a total of 8 basic steps. While step 6 and step 8 are dominantly business driven phases, the business aspect is a constant throughout the entirety of the fashion design process.

The term "fashion design entrepreneur" is used to describe an independent/self-employed fashion designer who possesses entrepreneurial skills and capability to run a fashion business. In reference to Yates (2011), the self employed/non-employed fashion design entrepreneur is categorized into 2 types known as the "freelance designer" and the "own-label designer". The own-label designer differs from freelance designers where releasing or starting an original fashion brand with its own label is the end goal. For this study the type of fashion design entrepreneur being focused on is the own-label designer, however this does not mean that the freelance designer is completely omitted out as general information provided are not entirely exclusive to own-label designers alone.

\subsubsection{Fashion Entrepreneurship \& Entrepreneurial Qualities}

Deriving from the word "entrepreneurship" which generally means the process of developing, managing and running a business venture from its conception, "fashion entrepreneurship" fits better in the context defined by Davidsson (2007, as cited in Ünay \& Zehir, 2012) as the process of exploiting opportunities existing in the environment or that are created through innovation in order to create value. A "fashion entrepreneur" is what people call the person who runs a business venture in the fashion field, regardless of what fashion business they operate or own.

To be a capable and successful fashion designer and entrepreneur, there are a number of skills that a fashion design entrepreneur must possess. They can be referred to as "fashion entrepreneur skills. Fashion designers need to have technical know-how, commercial sense and interpersonal skills (Yates, 2011), alongside possessing a variety of skills ranging from creative, technical, management and business skills. It should also be remembered that while not all fashion design entrepreneurs will be competent at all skills, most will excel in certain areas and at the very least has understanding of other areas.

\subsubsection{Fashion Business}

"Fashion business" according to Stone (2012) is a broader term which includes all services and industries connected in fashion from design, manufacturing distribution, marketing, retailing, advertising, communications, publishing and consulting-any business concerned with fashion goods or services. "Fashion business" in the context of business ownership means a business that is fashion oriented. The important elements from the business standpoint that needs to be planned and analyzed areas categorized below:

1. Marketing: market, target customer, unique selling proposition (USP), sales strategy, trademark, competitive analysis, others

2. Operations: materials \& resources, quality control, production specifics, \& amount, contractors \& suppliers, technology needs, support system, others

3. Finance: starting capital, accounting details, financial statements, cash flow, maintenance cost, insurance, tax liabilities, others 
4. Human Resource Management: business partnerships \& advisors, employees, professional services, industry network, others

\subsubsection{Fashion Industry}

The "fashion industry" is defined as the businesses engaged in manufacturing the materials and finished products used in the production of apparel and accessories (Stone, 2012). Sometimes the fashion industry may be specified as the "designer fashion industry" (DFI) when the focus of the fashion industry centers on fashion designers (Mills, 2018). Yates (2011) explained the simple breakdown of the fashion industry through 3 key distinctions: type of business, kind of employment, and garment categories.

\section{Research Methods}

\subsection{Analysis Model}

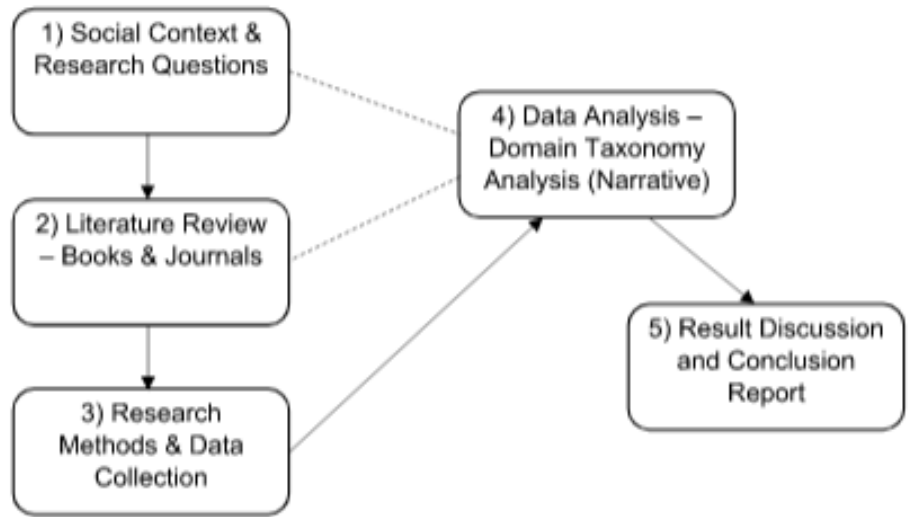

Figure 3.1. Simple Descriptive Research Analysis Procedure

Source: Bungin et al. (2020)

\subsection{Research Approach \& Design}

In order to gain knowledge and insight revolving around the fashion design entrepreneur thoroughly from a variety of perspectives, this study shall be conducted using the qualitative research approach. The qualitative approach and narrative design are appropriate methods for this research study as the exploratory nature of qualitative research seeks to amass knowledge of what is unknown or bringing insight to subjects that require deeper understanding. In addition, integrating stories and experiences from people's lives with personal experiences to make a cohesive, collaborative narration is key to make findings rich and plentiful to share while being real and relevant for other people in their particular experiences.

\subsection{Research Subject \& Informant Sampling Method}

As the subject of research revolves around fashion design entrepreneurs the selected participants who are an appropriate fit for this study are specifically limited to individuals who are fashion design entrepreneurs themselves with existing operating fashion businesses with involvement and experience in the fashion field who could provide insight to fashion design, fashion business, fashion entrepreneurship and the fashion industry in an Indonesian setting. The sample of individuals participating in this study are all Indonesian fashion designers who possess years of experience working as fashion design entrepreneurs. The designers in question are also still actively involved in running their fashion labels in different degrees and have contributed their knowledge and creativity both in the Indonesian fashion industry and fashion education.

In order to get the informants to be a participant of this study, a combination of the purposive approach and the snowballing approach of informant gathering method was chosen for this research. The purposive approach, as implied by its name decides informants who qualify to be interviewees according to the chosen research topic by specifically choosing a "key person" knowledgeable in regards to a certain issue or topic that is relevant to the subject (Bungin, 2007). The snowballing approach, on the other hand mainly relies on a "networking" system in order to find and recruit other potential study participants or other people who may know potential candidates willing enough to participate and contribute their share of information (Bungin, 2007). By a combination of these two 
methods it is possible to get rich amount of information from both acquainted and unacquainted fashion design entrepreneurs who are knowledgeable or experienced on the subject from various perspectives.

\subsection{Reliability \& Validity Test}

There are 3 primary requirements mandatory to be fulfilled while the remainder are additional secondary requirements that provide better qualifications for a potential participant.

Primary Requirements:

1) A fashion design entrepreneur (FDE) who owns their own personal fashion label, regardless with freelance work or not

2) Fashion brand label/business and FDE's residency set in Indonesia as main base of business operations

3) FDE's fashion brand label/business has been active for at least 2 years

Additional Requirements:

1) FDE has been involved with the fashion design industry for at least 5 years

2) FDE has created a minimum of 2-3 design collections or a number of custom designs according to design specialization during their business run

3) FDE has extensive knowledge and is highly experienced in various fashion or business themes as an FDE

*Note: Financial performance of business and capability is not a main requirement in the qualification list as one of the explored factors during inquiries with informants

\subsubsection{Triangulation}

Triangulation is a process where a number of different research and analysis methods are used for a study with the premise where data is validated by cross verification of two or more sources (Benson, 2017). Another understanding of triangulation according to Ritchie et al. (Ritchie et al., 2013), was that triangulation is also categorized as an external validation method that uses the assumption of using various sources of information to assist in confirming and improving research findings. The generally known 4 method forms of triangulation encompasses:

1) Methods triangulation,

2) Triangulation of sources

3) Triangulation through multiple analysis

4) Theory triangulation,

followed afterwards by a member or respondent validation (Denzin, 2017). In this research study triangulation of sources was the method form that fits as it involved the comparison of data from differing qualitative sources such as interviews, observations, and documented accounts (Ritchie et al., 2013). Three other advisors who are experts in their subject fields of fashion, business and qualitative research were also involved in the validation process by cross examining findings, assisting in data interpretation and analysis from different aspects.

\subsection{Data Collection Method}

This study utilizes interviews as the primary method to collect data. The interview process is simply defined as a process of gathering information through conversation (Easwaramoorthy \& Zarinpoush, 2006). This method encourages respondents to share more of their experiences and opinions without being influenced by external biases when inquired about specific matters, making interviews in general to be the perfect tool of inquiry (Easwaramoorthy \& Zarinpoush, 2006). For this particular study, a semi-structured in-depth interview is the type of interview chosen. The semi-structured interview format is an approach to the interview process which allows a more flexible approach by allowing unanticipated responses and exploration of spontaneous issues though open-ended questioning (Ryan et al., 2009).

\subsection{Data Analysis Method}

The qualitative approach of this research already predetermined a qualitative analysis method. Since the qualitative analysis methods have many variations and subtypes appropriate to analyze different core topics, manual analysis remains to be the primary, general analysis method chosen for this research, but is done according to the simple design model instead. The specific technique of manual analysis for this research however, is done through a combination of both domain analysis and taxonomic analysis. The combination of both analysis techniques is also 
known as "domain taxonomic analysis", or more well-known as "thematic analysis" in qualitative circles. Proper grouping that makes themes, sub-themes, categories and other codes would be identified accordingly.

\section{Result and Discussion}

\subsection{Analysis Results}

After proceeding with all means viable means of information gathering, cross-examining several source materials, interpretive and analytical thinking, and theory development conducted with meticulous detail and precision, analysis efforts resulted in the development of a visual representation based on gained information that was meant to highlight the overall connection of various factors, elements and themes that were discovered and determined during research. The primary contributions that came with this research came in form of two distinctive conceptual diagrams revolving around the research subjects of fashion and fashion business sustainability as a new model theory. Both conceptual diagrams included the focused subject with all related themes, sub-themes and minor themes around fashion and fashion business sustainability respectively.

Main purpose of the results depicted in form of conceptual diagrams aside from research method is to successfully illustrate the connection and relationship between all involved themes and sub-themes with accuracy and precision.

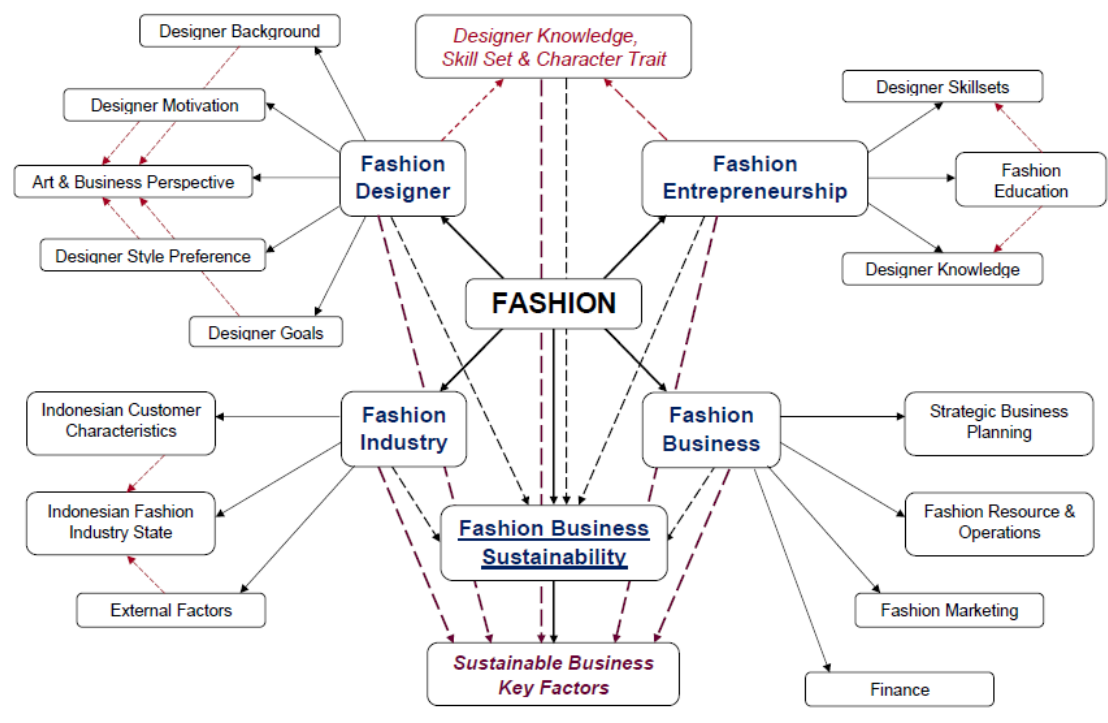

Figure 4.1. Fashion Business Sustainability Conceptual Diagram Source: Gathered \& processed data

\section{Legend}

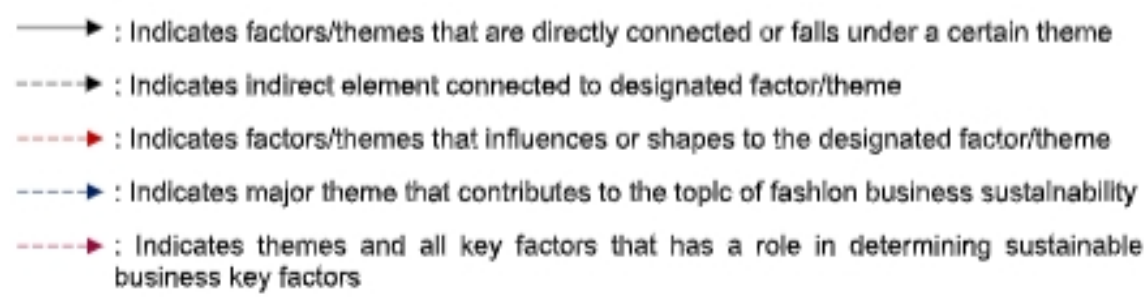

The first conceptual diagram displays the main topic subject of Fashion in central position as the source of all other related fashion themes. Four major themes that are involved and integrated with fashion include 1) Fashion Designer; 2) Fashion Entrepreneurship; 3) Fashion Business and 4) Fashion Industry. The four majorgeneral fashion themes share commonalities in certain themes and elements that are all involved in shaping the theme centered around Fashion Business Sustainability, and in turn also determining Sustainable Business Key Factors.

The first theme is the Fashion Designer, also known as the individual who has an interest and passion towards fashion and has a desire to be a fashion designer by trade. The fashion designer as a unique individual each 
has different circumstances that shape who they are as a creative person and their outlook and stance on certain issues and subjects. Depending on their personality, desires, and upbringing such as background, personal goals, driving motivation and personal style among other factors, it may also influence their mindset and future goals with their stance on artand business paired with how they choose to approach fashion design and creative self-expression. Character qualities of fashion designers receive special attention aspossessing them will be a major deciding factor for the fashion designer in confronting various challenges and running a fashion business.

The second theme is Fashion Entrepreneurship, meant to tackle the entrepreneurial side of fashion with the involvement of business aspects and fashion education. For fashion designers to be business entrepreneurs who are knowledgeable about the involvement of business in fashion, they require knowledge and skill set about fashion design and a business to a certain degree that they are able to function by the time of integration into the fashion industry and starting a personal fashion business. This is where fashion education comes into play and provides the space and environment for potential designers to take up all important fashion skills and knowledge, they have to hone their own selves while also taking advantage of business opportunities, experience and exposure. Certain character traits and entrepreneurial spirit will also be shaped in the process.

The third theme is Fashion Business, centered on the career and jobs involved with fashion, in particular working as a fashion designer and relating to business aspects. Fashion designers who work independently or with others will experience and learn from them if they decide to start their own fashion label where all business aspects will be handled with them as the lead and final decision maker A fashion business while sharing generally similar business functions such as business planning, marketing, operations human resources and finance, there aresome differences that only apply in fashion such as the inclusion of higher creative aspect and how operations and human resources are interchangeable among others. The challenges that arise in planning and running the fashion business successfully are the biggest issues every fashion designer must be prepared to face and counter.

The fourth theme is Fashion Industry, in which fashion and business truly can be seen operating in conjunction and the environment that influences theprogression of fashion and the people involved in the industry move in a very fast pace. Paying attention to all the rapid changes of the industry as a whole and especially in the specific country of region is crucial for fashion designers in deciding next projects, events and taking a variety of business moves. As the fashion industry is not directly related to the fashion designer and the internal business functions managed due to being external factors, being alert with the characteristics of the people and external factors such as economic state, political state and others is needed as the two will be influencing what the current state of the fashion industry. This will give significant impact especially in nearby or surrounding locations by driving the direction of fashion progression and indivertibly, the conditions of fashion businesses in the near future.

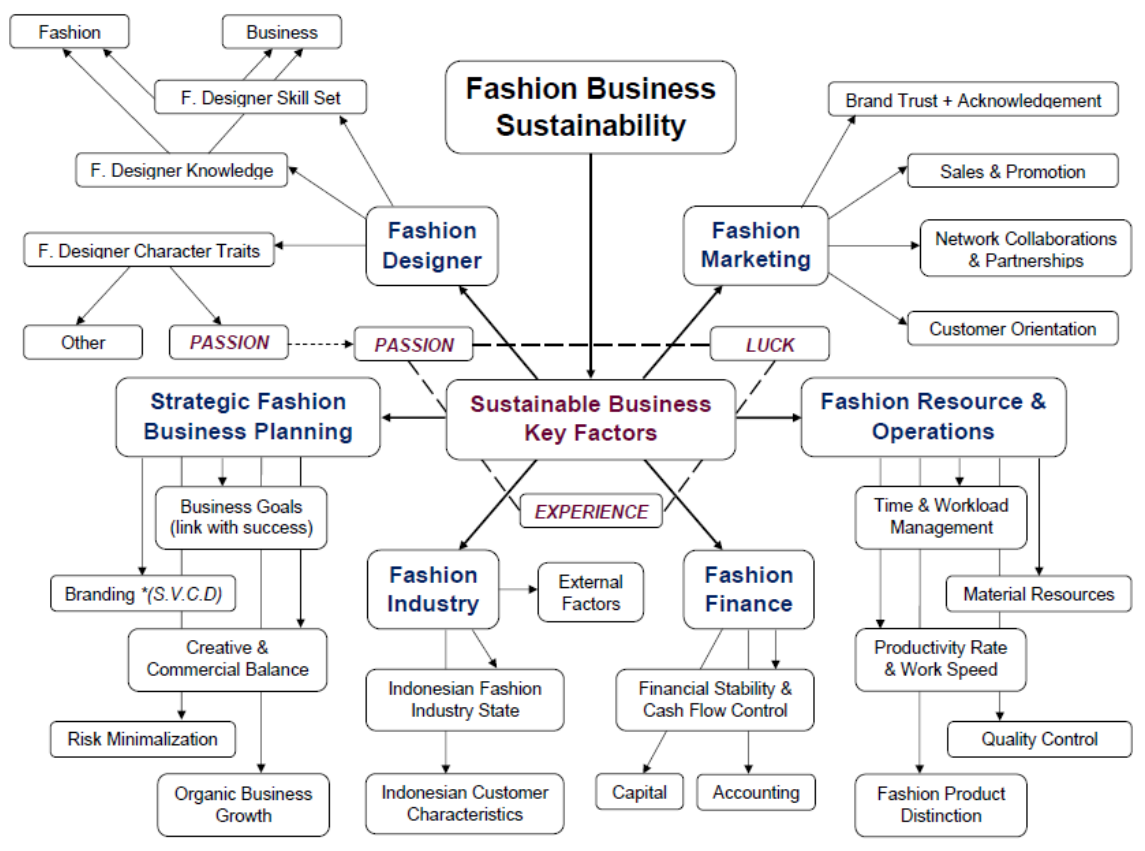




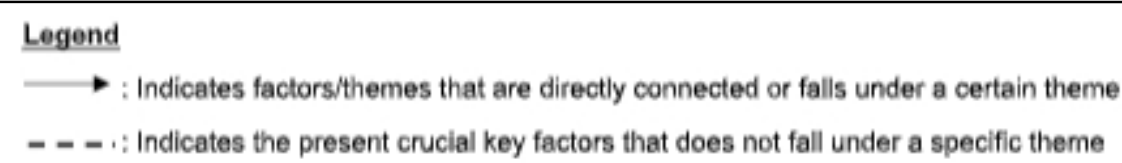

Figure 4.2. Fashion Business Sustainability Conceptual Diagram Source: Gathered \& processed data

The themes in question are: 1) Fashion Designer; 2) Strategic Fashion Business Planning; 3) Fashion Resource \& Operations; 4) Fashion Marketing; 5) Fashion Finance (also read as only finance), and 6) Fashion Industry. All six themes were categorized retaining the focus subject of fashion business sustainability.

The first theme once again is Fashion Designer. In this particular theme the addition of sustainability as a key element of focus narrows down what fashion designers need to possess to run a fashion business that will sustain itself. Taking account both personal fashion designer aspects and fashion entrepreneurship aspects, three core key factors any fashion designer must possess boils down to knowledge and skill set from both fashion and business and character traits or qualities with special mention regarding passion as the first and most important key element as the primary source of driving motivation for all fashion designers. Aside from knowledge which is usually broad and positive character traits which are all needed regardless of career, the skill set fashion designers need to master in particular is quite extensive, detailed and specific for peak performance and mastery. Referencing Burke's findings in form of the fashion designer's portfolio of skills that was covered early on in chapter II, the listed fashion and business skills that range from creative, technical, business and management respectively remain as the general basic standards for a qualified fashion designer which serves as a guideline.

The second theme is Strategic Fashion Business Planning. Business planning has remained as the primary backbone of business identity prior to covering other business functions. In short, good business planning done with strategic consideration in mind is the first crucial step to properly establishing the fashion business from the very start and obtaining the key factors of business sustainability.

After having the idea and planning for a fashion business in mind, there are five core key factors that are deemed as crucial for the business and must be accounted for during business planning with a strategic edge. The very first step lies in the business of label's branding which includes brand story, vision, mission, values, character and distinction that were properly thought and planned from the start. In conjunction with branding, business goals and priorities must be set accordingly alongside the direction of the business. During the business run and executing various tasks maintaining creative and commercial balance throughout must be consistent, and all possible methods of risk minimalization in a calculated way will ensure higher chance of business survival. By keeping all four previous key factors in mind and progressing step by step with repetitive assessments, the last factor; organic business growth will be apparent to signify a strong sign of the fashion business' sustainability.

The third theme is Fashion Resource and Operations; a combination of the business functions of operations and human resources with the additional emphasis on material resources accounted for to suit the fashion-oriented perspective. Fashion production being the most taxing and time-consuming part in running a fashion business requires five core key factors to keep the entire production process under control while being able to continuously present the best product outcome. Time and workload management is stressed to be the most crucial key factor that will also determine productivity rate and work speed which is also another factor meant to be done as effectively as possible. Throughout the design and production process fashion product distinction must remain intact as a selling point; this can only be highlighted by also maintaining tight quality control throughout the production process and incorporating the best and appropriate material resources while keeping track of stock inventory. If all mentioned key factors are fulfilled with properly controlled production management process with the addition of consistency, the fashion business sustainability rate will continuously improve in time.

The fourth theme is Fashion Marketing. This particular theme is noted to possess a dynamic nature compared to other mentioned themes that are more rooted in consistency instead of adaptability to a certain degree. Five key factors remain consistent; sales and promotion being the first to mention as a staple of marketing provides the most variety in viable promotional methods that are compatible depending on the business context to help build the fashion business grow exponentially. Networking, collaborations and partnerships are also another crucial factor to be taken 
into consideration in marketing as it opens to even more opportunities to build and promote the fashion business. By taking special attention and care towards customer orientation, other two key factors in form of brand trust and brand acknowledgement will also grow as time pass; influencing fashion business sustainability in the longer run.

The fifth theme is Fashion Finance, also known as finance due to the lack of difference despite the fashion context. While having the least points to cover due to how straightforward the focus is, finance remains as one of the decisive factors that dictates all possible actions while running the business, making it extremely crucial in shaping and maintain long-term business run and fashion business sustainability.

Only three key factors are involved in finance, firstly being the possession of a considerable amount of capital itself which could be gathered by a number of methods to start the fashion business. This is paired with the process of bookkeeping, specifically in accounting where every decision affects cash flow in income, expenditure, and other things. The combination of the two key factors are the components of the third key factor: financial stability and cash flow control. Financial management and accounting are usually the parts many fashion designers struggle with to varying degrees, necessitating support and help from other people as the fashion business operate and grow to minimize all risks and support organic growth; a sure fire step to long-time fashion business sustainability.

The sixth and final theme is Fashion Industry. This particular theme possesses an external characteristic compared to all other themes which are more internal-oriented. There are three important key factors to pay attention to at all times; the first by identifying all external factors such as the economic state, political state, social issues and several others that guarantees impact to a certain degree to the fashion business in both positive or negative ways with change. The second is understanding and identifying general customer characteristics based on location and taking account of the demographics and habits of people. The final is the current state of the fashion industry itself; influenced and driven by the other two mentioned key factors. Knowing, understanding and being able to identify all influencing factors that shapes the industry as a whole and in specific regions are vital for strategic fashion business planning with adaptability and flexibility to ensure fashion business survival and sustainability.

There are also crucial key factors which will be essential to the fashion business's due to their inclusion throughout the business run. The first extremely crucial factor is Passion, tied together and working in tandem with the presence of innate artistic talent to a certain degree. While talent and skill in design and arts will be extremely helpful in being a capable fashion designer, that alone will not be the ultimate decisive factor of success. Without passion involved, all the work done will feel meaningless, pointless and void of enjoyment and interest. Experience is also as crucial, as it is through life-long learning, encountering challenges and dealing with mistakes or failure that a fashion designer learns how to survive with all knowledge and skills gained while maintaining and improving attitude and good character. The final crucial key factor is luck, where it is decided by preparation and chance that coincides at the right moment which fashion designers must take advantage of to reach and achieve their goals.

The possession and control of all key factors and components will determine a fashion business' success and long-term sustainability. This also includes proper consideration in regards to the various tactics or methods of execution available at hand. Fashion designers must keep in mind while managing their fashion businesses that not all tactics or methods will be accessible or suitable as it will be dependent on circumstances. Being able to properly assess the overall situation at hand and taking calculated, thought out steps will determine how the fashion business will survive. With the addition of maintaining consistency and hard work, it will be a guarantee for a business to survive, grow organically and sustain itself for long time.

\section{Conclusions and Practical Implication}

After thorough research and detailed analysis about fashion and its business sustainability by relying primarily on the responses given by interviewed respondents coupled with literary findings, the researcher had reached the following conclusions. In order for a fashion business to achieve success, an organic business growth and long-term sustainability, the fashion business must possess and have control of the various themes and activities that encourage business sustainability that fall under fashion in the form of sustainable business key factors. The fashion designer needs to possess a vast knowledge of both fashion and business in various aspects, have a mastery or overall prowess in a number of fashion and business-related skill sets, and an array of positive character qualities or traits paired with an entrepreneurial spirit. The fashion designer must know different business areas, have a 
constant presence and be highly involved as a business owner to run the business effectively, compete, and be able to identify and deal with the various types of business challenges that vary from production, marketing, finance, and business planning. Observing the fashion industry from both general and in-depth perspective is crucial to understanding how the industry functions as a whole and in specific based on a certain scope to successfully establish and run a sustainable fashion business.

\section{References}

Benson, K. (2017). Black fashion designers matter: A qualitative study exploring the experiences of Black female fashion design entrepreneurs. Iowa State University.

Bungin, B. (2007). Penelitian kualitatif: Komunikasi, ekonomi, kebijakan publik, dan ilmu sosial lainnya (2th ed.). Jakarta: Kencana Prenada Media Group.

Denzin, N. K. (2017). Sociological methods: A sourcebook. Routledge.

Easwaramoorthy, M., \& Zarinpoush, F. (2006). Interviewing for research. In Canada Volunteerism Initiative. Imagine Canada.

Kasim, A., Bungin, B., Dzakiria, H., \& Mokhtar, M. F. (2020). Metode penelitian pariwisata dan hospitality. Jakarta: Kencana.

Mills, C. E. (2012). Navigating the interface between design education and fashion business start-up. Education and Training, 54(8), 761-777. https://doi.org/10.1108/00400911211274873

Mills, C. E. (2018). Grappling with the challenges of start-up in the designer fashion industry in a small economy: How social capital articulates with strategies in practice. In Creating Entrepreneurial Space: Talking Through Multi-Voices, Reflections on Emerging Debates (pp. 129-155). Emerald Publishing Limited. https://doi.org/10.1108/S2040-72462018000009A008

Ritchie, J., Lewis, J., Nicholls, C. M., \& Ormston, R. (2013). Qualitative research practice: A guide for social science students and researchers. Thousand Oaks CA, London: SAGE Publications.

Ryan, F., Coughlan, M., \& Cronin, P. (2009). Interviewing in qualitative research: The one-to-one interview. International Journal of Therapy and Rehabilitation, 16(6), 309-314.

Smal, D., \& Lavelle, C. (2011). Developing a discourse in fashion design what is research for fashion design? The Sixth International DEFSA Conference Proceedings, 192-198.

Stone, E. (2012). In fashion (2nd ed.). United States of America: Fairchild Books, Inc.

Ünay, F. G., \& Zehir, C. (2012). Innovation intelligence and entrepreneurship in the fashion industry. ProcediaSocial and Behavioral Sciences, 41, 315-321.

Yates, J. (2011). The fashion careers guidebook. North America: Barron's Educational Series Inc. https://books.google.co.id/books?id=JQ1HYgEACAAJ 